\title{
How Parents Perceived the Tutoring Education-A Study in Taiwan
}

\author{
Gwo-Hau Ding ${ }^{1}$, Chiou-Fong $\mathrm{Wei}^{2}$, Chien-Cheng $\operatorname{Lin}^{3, *}$ \\ ${ }^{1}$ Dept. of Public Relations, Nanfang College •Guangzhou, Guangzhou, China. \\ ${ }^{2}$ Business School, Nanfang College 'Guangzhou, Guangzhou, China. \\ ${ }^{3}$ College of Accounting, Nanfang College 'Guangzhou, Guangzhou, China. \\ *Corresponding author. Email: ylcuser@yahoo.com.tw
}

\begin{abstract}
This study explores how parents perceive and accept the tutoring education by drawing on the Theory of Planned Behavior (TPB). It proposed a model illustrating how parents of junior high school students are affected from attitude, subjective norms, perceived behavior control and perceived public education policy changed. An online survey was implemented in Taiwan to collect data and PLS-SEM was used to check the validated data and analysis the model. The results contribute that the four independent variables, "attitude toward behavior", "subjective norm", "perceived behavior control", and "perceived public education policy change", can promote the parents' behavioral intention to accept tutoring educations. Tutoring industries are suggested to employ corresponding business strategy to effectively manage customer's intention and relationship.
\end{abstract}

Keywords: Tutoring education, Theory of planned behavior, Public education policy.

\section{INTRODUCTION}

The expansion of private tutoring beyond the formal schooling has become an increasing status happened in many countries (Kim, Gough \& Jung, 2018). Mori and Baker $(2010$, p. 37) described the tutoring education "was also thought to be the 'secret ingredient' in some Asian nations' relative high performance." In Asian countries, it is called "shadow education", but terms such as "tutoring education" "supplement education" and "private tutoring." (Pinar, 2011) Increasing demand for tutoring education is particularly tremendous in East Asian areas, such as China, Taiwan, Japan and South Korea. There are deeply rooted in the Confucian culture and highly competitive, which emphasize education and diligence (Kim \& Lee, 2010; Liu, 2012). Mark Bray's $(1999,2011)$ studies demonstrate tutoring education is pervasive worldwide, Mori and Baker (2010, p.39) mentioned numerous studies show it is "occurring at the worldwide level."

Taiwan's students have participated the tutoring education for a long time for the following reasons: (1) the far-reaching impact of academicism (2) the inheritance and accumulation of cultural capital (3) the close relationship between diplomas and career, which increase reasons for the booming of tutoring educations (Liu, 2006).

Taiwan opened the political ban and social restrictions since 1987, the society have proposed the reform demands and started the so-called "education reform" for more than 30 years. However, its evaluation is not high. "The results of each education reform programs are not consist and meet with the nature of education ... The volatility of policies has left parents, students, and teachers at a loss, and the original problems have not been solved, but new problems have been created." (Xu, 2014) The changing in public education policies has impacted on parents' choice of tutoring educations since it has influence on the education system.

There were many studies analyzed the demand side of tutoring education, but have few discussions on the supply side of tutoring, i.e., the management and operation of tutoring institutions, (Liu, 2018). This research contributes the management of tutoring education industry by surveying relationship between parents' attitudes, subjective norms and perceived behavior control among parents of different groups. Next, it intends to analyze the changes in public education policies and their impacts significantly affect parents' consumption intention and behavior, which in 
turn will influence the development of tutoring educations. Third, it wants to enhance the cognition of tutoring education for its future business strategies via providing the complete understanding of consumer perception and intention.

From TPB, it was proposed that "attitude belief" has a significant positive effect on "behavioral intention" to a certain extent. Therefore, this study believes that the more positive the attitude belief, the stronger the behavioral intention. If this result is combined with "parents' consumption tutoring behavior." It is surveyed whether the parents' "attitude toward behavior" has a positive effect on their children's "tutoring consumption intention."

The subjective norm refers to "social pressure that we perceive about whether to engage in a certain behavior". Ajzen $(1985 ; 1991)$ proposed that subjective norm will positively influence the intention to behavior. This social pressure comes not only from parents, siblings, friends, or peers, but also from the social environment, therefore it integrated with the "parent's consumer tutoring behavior", and put forward to test whether parents' "subjective norms" has a positive effect on their children's "tutoring consumption intention."

Ajzen $(1985 ; 1991)$ also argues that the more positive the perceived behavior control, the higher the degree of positive influence on behavior intention. It is observed that perceived behavior control and behavior intentions will have a positive influence on the ultimate behavior, but also effect the behavior that cannot be completely under the control of will. This study also intend to know whether parents' "perceived behavior control" has a positive effect on their children's "tutoring consumption intention."

The above surveys are studied on consumers' own cognition, however, as far as the society concerned, the changes and impacts of the external environment in Taiwan has greatly influenced the education environment, and caused parents and students to become maladaptive and confused, which has undergone successive educational reforms over the years. This study put it in as a significant influence factor on education, and inferred that their "perceived public education policy change" will be an influence on parents' willingness to put their children in tutoring. Then the parents' "perceived public education policies change" is tested whether has a positive effect on "tutoring consumption intention."

\section{METHODS}

\subsection{Methods}

The study applied Partial least squares structural equation modeling (PLS-SEM) for maximum estimation of the explained variance of the dependent variables rather than model fit. It was used to evaluate our measures and the proposed model (Hair et al., 2011). When prediction is the goal of the research, PLS is also highly suitable for exploratory research because it requires few demands to test scales, sample size, and residual redistributions (Henseler et al., 2009).

\subsection{Sampling and Data Collection}

To analyze the attitudes, subjective normative and perceived behavior control and consumption intentions of parents of senior high school students on supplement education consumption behavior, the measurement items were derived to fit TPB. Meanwhile, to considerate the public's cognition of education policy change, some questions are referred from Chen's (2014) research.

The research was divided into pre-test and formal questionnaires, the formal one is targeted at parents of junior high school students in Taiwan. The data were collected through an online survey which were posted on many education and tutoring societies in Facebook and some chain tutoring schools. A total of 398 respondents took part in the survey as a convenient sample. Among them, 25 questionnaires were excluded due to redundant identities or incomplete answers. A total of 373 valid questionnaires were obtained, with a response rate of $93.71 \%$.

\section{RESULT AND DISCUSSIONS}

\subsection{Model Measurement}

Cronbach's $\alpha$ (Alpha; Cronbach \& Meehl, 1955) and Composite Reliability (CR) were used to measure the reliability of the internal consistency of the measurement, and test Convergent Validity and Discriminant Validity (Hair, etc., 2014).

Table 1. Reliability and Validity of Constructs

\begin{tabular}{|c|c|c|}
\hline Constructs & Alpha CR & AVE \\
\hline ATB & $0.728 *-0.890 * 0.9260 .938$ & 80.629 \\
\hline PBC & $0.800 *-0.856 * 0.9100 .929$ & 90.687 \\
\hline PEP & $0.895 *-0.950 * 0.9160 .946$ & 60.855 \\
\hline $\mathrm{CI}$ & $0.749 *-0.886 * 0.8930 .921$ & 10.701 \\
\hline $\mathrm{SN}$ & $0.757 *-0.882 * 0.8750 .910$ & 00.669 \\
\hline
\end{tabular}

In Table 1, the data provide a measure of the reliability and validity of the measurement model. The smallest load factor is 0.728 , which is significant. The minimum AVE is 0.629 (behavior attitude), and the minimum consistency reliability (Alpha) is 0.875 (subjective norm), which also meets Fornell and 
Larcker's requirements (0.6), and every project load is higher than 0.7. The factor loading of the potential variables in this table is between 0.728 and 0.950 . The individual item reliability is good; the combined reliability $(\mathrm{CR})$ of the four facet factors are $0.938,0.910$, 0.929, and 0.946; Average Variance Extracted is 0.629, $0.669,0.687$, and 0.855 , respectively. Shows that this scale has a fairly high reliability and convergent validity.
Table 2 shows the maximum correlation coefficient is 0.763 , which is lower than the critical value of 0.924 (Hair et al., 2010), so there is no multicollinearity problem. It also shows that all indicators strongly load its construct, and there is no stronger correlation with other construct. Meanwhile, the numbers confirm that the reliability, convergence and discriminative validity of the measurement model are satisfactory.

Table 2. Squared correlation matrix of constructs

\begin{tabular}{llllll}
\hline Constructs & ATB & PBC & PEP & CI & SN \\
\hline ATB & $\mathbf{0 . 7 9 3}$ & & & & \\
PBC & 0.763 & $\mathbf{0 . 8 2 9}$ & & \\
PEP & 0.012 & 0.147 & $\mathbf{0 . 9 2 4}$ & \\
CI & 0.655 & 0.671 & 0.275 & $\mathbf{0 . 8 3 7}$ & \\
SN & 0.657 & 0.593 & 0.017 & 0.733 & $\mathbf{0 . 8 1 8}$
\end{tabular}

Note: Bold number on the diagonal indicate the AVE of construct, while the others are the squared correlation coefficients between variables

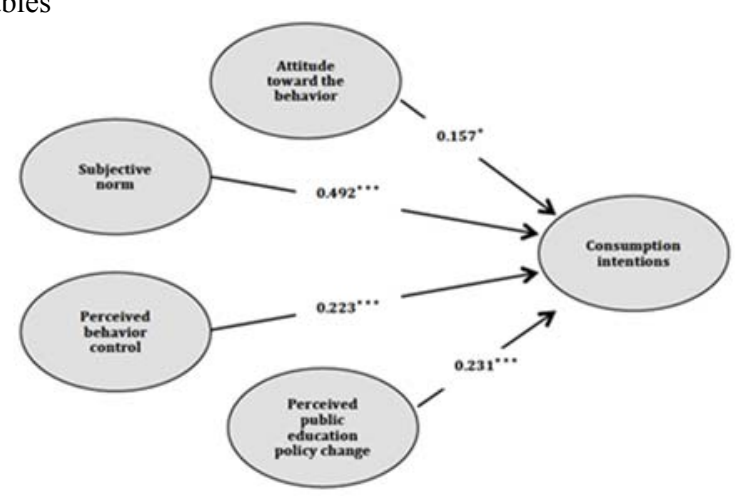

Figure 1 Result of SEM testing.

\subsection{Analysis Result of Structural Equation Modeling}

According to Figure 1, it is found that "attitude toward behavior " has a direct effect on "consumption intention" with its path coefficient of $0.157^{*}(\mathrm{p}<0.05)$, and "subjective norms" have a direct effect on "consumption intention" with its path coefficient of $0.492 * * *(p<0.001)$. And "perceived behavior control" also has a direct effect on "consumption intention" with its path coefficient of $0.223 * * *(p<0.001)$, and finally the "perceived public education policy change" also has a direct effect on "consumption intention" with its path coefficient of $0.231 * * *(\mathrm{p}<0.001)$.

Totally it showed that the more the parents agree with "attitude toward behavior", "subjective norms", "perceived behavior control" and "public policy change awareness," their perspective on "tutorial consumption intentions" will become more positive. Therefore, based on the results of the path correlation coefficients of the above five dimensions, it can be inferred that the 4 variables are effective on consumption intention.

\section{CONCLUSIONS}

\subsection{New Independent Variable "Environment Change"}

TPB proposed "attitude toward behavior," "subjective norms" and "perceived behavior control" are positively effect on "consumption intention." However, TPB did not considerate the perspective of environment factor because in most of the purchasing process, people usually can perceive and control their decision making procedure. In this research, "perceived public education policy change" was added as a new independent variables which stands for the outside environmental factors for parents who can not control the environment but they know it is important. Therefore the survey proposed, and get confirmed, that in some issues or products need to considerate the outside environment factors which cannot be controlled, it should put the environment factors into the decision-making model.

\subsection{Strategies Suggestions for Tutoring Industry}

The results show, the more of the four main variables, the more positive the "consumption intention", then to affect "consumption behavior". Therefore the tutorial education should create a good attitude toward the behavior for the students' parents. The tutoring need to help children to enhance the study ability in cognition, which to make parents perceive the assistance for their children, and these will produce parents' positive impressions. Then the students' parents do not easily 
accept the opinions from social interpersonal networks, but willing to spread the word-of-mouth. Parents demonstrate a strong autonomy to choose the tutoring class, and expect the children make progress in the tutoring. Parents also agree that tutorial education can add future competitiveness and quickly solve problems ability. And they hope that tutoring can help students effectively strengthen the deficiencies of current school education and increase their multi-learning pathways.

The results indicate that the frequent changes in the public education policy are not fully understood and identified by parents, which leads parents to seek assistance from the tutoring class. The tutoring industry should quickly echo the changes to help parents and students understand and respond to the changes. Finally, if parents' attitude towards children in the tutoring class is satisfied, they won't change, and if parents feel that their children were taken care of by the tutoring school and the studying attitude is satisfied, then they will stay, and recommend it to other relatives and friends.

Concluded from all, the four variations "attitude toward behavior", "subjective norm", "perceived behavior control", and "perceived public education policy change" are effective, parents will generate the consumption intention for the tutoring school, have the word of mouth, and continue their consumption behaviors. As a result, the tutoring school will continue a positive cycle and get in-depth promotion effects for their survival and future development.

\section{AUTHORS’ CONTRIBUTIONS}

Gwo-Hau Ding: Topic and research frame construction, theory finding, paper writing. Chiou-Fong Wei: Data collecting and analyzing, tables and figures building. Chien-Cheng Lin: coordination, publication finding, corresponding.

\section{REFERENCES}

[1] Kim, Y. C., Gough, N., \& Jung, J. H. (2018). Shadow education as an emerging focus in worldwide curriculum studies. Curriculum Matters Journal, 114, pp. 8-30, researchgate.net, https://doi.org/10.18296/cm.0027

[2] Mori, I. \& Baker, D. (2010). The origin of universal shadow education: what the supplemental education phenomenon tells us about the postmodern institution of education, Asia Pacific Education Review, 11, pp. 36-48.

[3] Foondun, A. R. (2002). The issues of private tutoring: An analysis of the practice in mauritius and selected South-East Asian countries. International Review of Education, 48(6), pp. 485515. https://doi.org/10.1023/A:1021374811658
[4] Kim, S. \& Lee, J. H. (2010). Private tutoring and demand for education in South Korea. Economic Development and Cultural Change, 58, pp. 259296.

[5] Bray, M. (1999). "The Shadow Education System: Private Tutoring and Its Implications for Planners." United Nations Educational, Scientific and Cultural Organization.

[6] Liu, J. (2006). The changes, efficacy, and stratification of tutoring in Taiwan, Educational Research Bulletin, 52(4), pp. 1-33.

[7] Xu, H. Y. (2014). Using systematic thinking to explore the impact of Twelve Years Compulsory Education exemption on Taiwan education. master thesis, Sun Yat-Sen University, unpublished, Kaohsiung.

[8] Liu, J. (2018). The development pattern and urbanrural differences of cram schools in Taiwan, Advances in Social Sciences, 7(11), pp.1.

[9] Ajzen, I. (1985). From intentions to actions: A Theory of Planned Behaviour, in action control from cognition to behaviour. In: Kuhl J., Beckmann J. (eds), Action Control. SSSP Springer Series in Social Psychology. Springer, Berlin, Heidelberg.

[10] Ajzen, I. (1991). The Theory of Planned Behaviour. Organizational Behaviour and Human Decision Processes, 50, pp. 179-211.

[11] Hair, J. F., Ringle, C. M., \& Sarstedt, M. (2011). PLS-SEM: Indeed, a silver bullet. Journal of Marketing Theory and Practice, 19(2), pp.139-152.

[12] Henseler J., Ringle, C. M., \& Sinkovics, R. R. (2009). The use of Partial Least Squares path modeling in international marketing. Advances in International Marketing, 20, pp. 277-319.

[13] Chen, Y. W. (2014). Research on the public's cognition of Twelve-Year Compulsory Education. Master's Thesis of the Institute of Applied Statistics, School of Management, Fu Jen University, Unpublished, New Taipei City.

[14] Cronbach, L. J., \& Meehl, P. E. (1955). Construct validity in psychological tests. Psychological Bulletin, 52(4), pp. 281-302.

[15] Hair, J. F. (2014). Partial Least Squares Structural Equation Modeling (PLS-SEM): An emerging tool for business research, European Business Review, 26(2), pp. 106-121. 